\title{
A fatal case of bipolar disorder and comorbid hepatitis C
}

\author{
Desislava A. Ignatova ${ }^{1}$, Georgi N. Onchev ${ }^{1}$ \\ ' Department of Psychiatry and Clinical Psychology, Medical University of Sofia, Sofia, Bulgaria. \\ Institution where the study was conducted: Department of Psychiatry and Clinical Psychology, Medical University of Sofia, St. G. Sofiyski 1, Sofia 1431, Bulgaria
}

Received: 7/19/2018 - Accepted: 10/30/2018

DOI: 10.1590/0101-60830000000181

Ignatova DA et al. / Arch Clin Psychiatry. 2018;45(6):167-8

\section{Dear Editor,}

Bipolar disorder is associated with an increased risk of substance use disorders and hepatitis $\mathrm{C}$ virus $(\mathrm{HCV})$ infection ${ }^{1}$. The prevalence of HCV in bipolar patients is 5 to 13 -fold higher than in the general population, presenting a major clinical and therapeutic challenge ${ }^{2}$. We report a case of a patient with bipolar disorder, a history of heroin addiction, and HCV related cirrhosis with fatal outcome.

\section{Case}

Mr. A was a 44-year-old married white male, an artist, who was diagnosed with bipolar disorder in his late adolescence. He had recurrent manic or mixed psychotic episodes, effectively treated with antipsychotics and mood stabilizers. During a ten-year period of intravenous heroin misuse and dependency, he contracted HCV and subsequently developed liver cirrhosis. Induction of psychotic exacerbation hindered specific HCV infection treatment, which continued with hepatoprotectors and diuretics with poor adherence. The patient's timeline is presented in Figure 1.

The last psychiatric admission of Mr. A was at the age of 44 . He presented with insomnia, elevated mood, megalomania, delusions, dysphoria, and lack of insight. Anaemia, thrombocytopenia, hypoalbuminemia, ascites and elevated transaminases were present. Zuclopenthixol resolved the psychiatric symptoms and the patient was referred to the hepatology department. A follow-up after one year was scheduled. The patient's wife reported that he had died. He had been in stable mood following discharge and discontinued the psychiatric treatment. The improvement in the mental state improved the compliance with the somatic treatment and regimen, which led to temporary stabilization of the somatic state. However, his somatic condition deteriorated and he died from liver failure 3 months prior to the scheduled follow-up at the age of 45 .

\section{Discussion}

Individuals with severe mental illness are estimated to die approximately 25 years earlier than the general population and up to $60 \%$ of the premature deaths are due to general medical conditions ${ }^{3}$. Chronic HCV infection is a major concern, with an estimated infection rate up to $10-23.3 \%$ in bipolar patients as compared to $1.8 \%$ in the general population ${ }^{4}$. The risk of liver cirrhosis is between 15 and $30 \%$ within 20 years ${ }^{5}$ but risky social environment, highrisk behaviors, and non-compliance can aggravate the condition in bipolar patients ${ }^{2}$.

New and highly effective therapies for chronic HCV infection are present, however access to treatment remains limited and psychiatric patients still suffer stigmatization ${ }^{6,7}$. Mental disorders were previously seen as contraindications against the use of interferon alfa and ribavirin in patients with chronic hepatitis $C$, as cases of mania and psychosis induced after initiation of treatment or upon withdrawal have been reported ${ }^{8,9}$. Current guidelines state that all $\mathrm{HCV}$-infected patients should receive treatment, with patients with life-threatening conditions not expected to survive beyond 1 year being the only exclusion ${ }^{7}$.

The case highlights the importance of an integrated model for clinical management of patients with comorbid HCV infection and bipolar disorder. An interdisciplinary approach and education of the patient are required in order to ensure the adequate treatment and compliance and prevent fatal outcomes ${ }^{10}$.
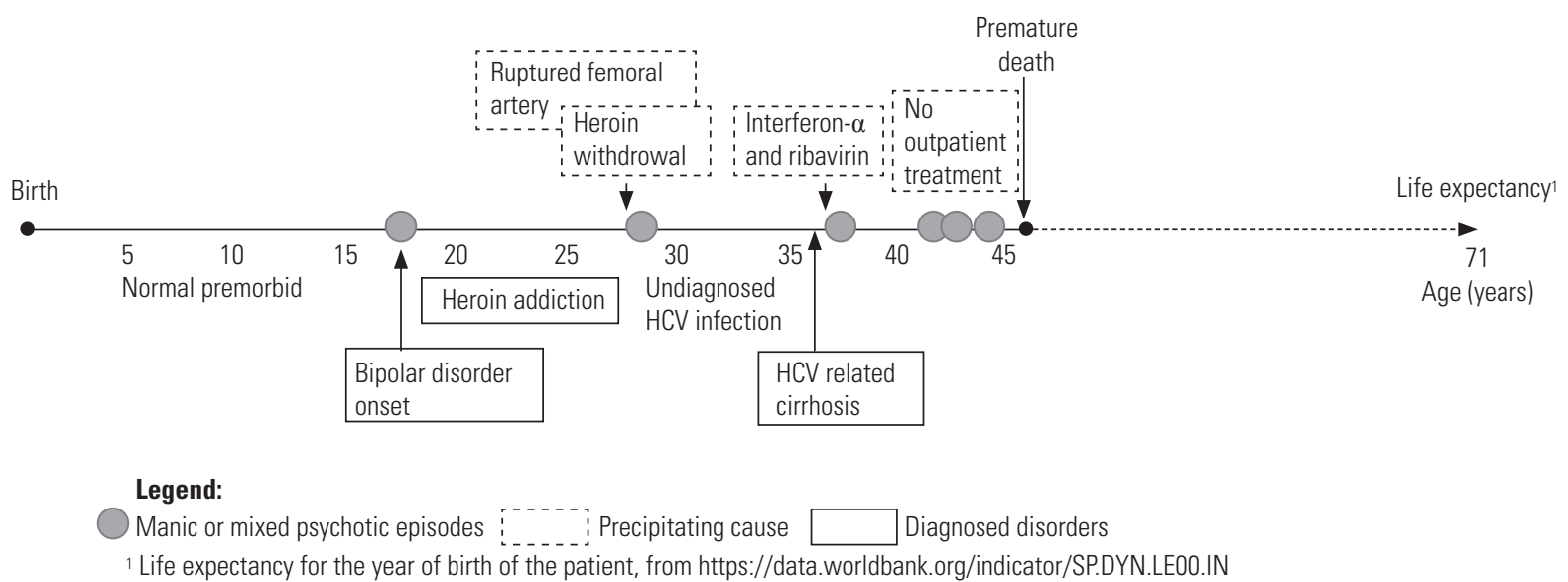

Figure 1. History of the patient. 


\section{References}

1. Yovtcheva SP, Rifai MA, Moles JK, Van der Linden BJ. Psychiatric comorbidity among hepatitis C-positive patients. Psychosomatics. 2001;42(5):411-5.

2. McLaren KD, Marangell LB. Special considerations in the treatment of patients with bipolar disorder and medical co-morbidities. Ann Gen Hosp Psychiatry. 2004;3(1):7.

3. Parks J, Svendsen D, Singer P, Foti ME, Mauer B. Morbidity and Mortality in People with Serious Mental Illness. 2006 [cited 2018 Jul 18]. Available from: www.nasmhpd.org.

4. Rifai MA. Hepatitis $\mathrm{C}$ treatment of patients with bipolar disorder: a case series. Prim Care Companion J Clin Psychiatry. 2006;8(6):361-6.

5. Lin $\mathrm{H}-\mathrm{C}$, Xirasagar S, Lee H-C, Huang C-C, Chen C-H. Association of Alzhemier's disease with hepatitis $\mathrm{C}$ among patients with bipolar disorder. Khudyakov YE, editor. PLoS One. 2017 Jun 16;12(6):e0179312.
6. Schaefer M, Schmidt F, Folwaczny C, Lorenz R, Martin G, Schindlbeck $\mathrm{N}$, et al. Adherence and mental side effects during hepatitis $\mathrm{C}$ treatment with interferon alfa and ribavirin in psychiatric risk groups. Hepatology. 2003;37(2):443-51.

7. Horsley-Silva JL, Vargas HE. New Therapies for Hepatitis C Virus Infection. Gastroenterol Hepatol (N Y). 2017;13(1):22-31.

8. Onyike CU, Bonner JO, Lyketsos CG, Treisman GJ. Mania During Treatment of Chronic Hepatitis C With Pegylated Interferon and Ribavirin. Am J Psychiatry. 2004;161(3):429-35.

9. Carpiniello B, Orru MG, Baita A, Pariante CM, Farci G. Mania induced by withdrawal of treatment with interferon alfa. Arch Gen Psychiatry. 1998;55(1):88-9.

10. Sylvestre DL, Loftis JM, Hauser P, Genser S, Cesari H, Borek N, et al. Co-occurring Hepatitis C, substance use, and psychiatric illness: treatment issues and developing integrated models of care. J Urban Health. 2004;81(4):719-34. 